\title{
Age at achievement of final height in greek young
}

\section{men}

\begin{abstract}
Background: Final height in boys is considered to be achieved, most commonly, at the age of 18 years. However, if one looks carefully at various growth charts may notice some increase in the mean height of boys from the age of 18 to 20 years. In this study we aimed at examining final height in a large sample of contemporary conscripts of the Greek Army.

Methods: The height of 3038 young men was measured in the year 2006. We explored our data using a lowess curve and after having taken into account its form, we adjusted a proper non-linear regression model to our data.

Results: The lowess curve showed an increment in the mean height up to the age of about 23 years whereas, after this age mean height seemed to be stable. The model that described adequately our data was: $\left(h=b_{1}\left(1-b_{2}{ }^{k}\right)\right)$, where $h$ is the mean height, $\mathrm{b}=180.16(95 \%$ C.I.: $179.33-180.98, \mathrm{p}<0.001), \mathrm{b} 2=0.823$ (95\% C.I.: $0.813-0.833$, $\mathrm{p}<0.001)$, and $\mathrm{k}=$ age in years.
\end{abstract}

Conclusion: Our study provides a hint against the established notion of growth ceasing at the age of about 18 years, in males.

Keywords: stature, final height, men, conscripts
Volume 2 Issue 6 - 2015

Konstantinos Douros,' Grigorios Fytanidis,' Barbara Boutopoulou,' loanna Loukou, ${ }^{2}$ Anastasios Papadimitriou'

'Department of Pediatrics, University of Athens School of Medicine, Greece

${ }^{2}$ Cystic Fibrosis Unit, “Aghia Sophia” Children's Hospital, Greece

Correspondence: Konstantinos Douros, Department of Pediatrics, "Attikon" Hospital Rimini Str, Chaidari I2464, Athens, Greece, Tel: +30 210 5832228; Fax: +30 210 5832229; Email costasdouros@gmail.com

Received: August 23, 2015 | Published: October 01, 2015

\section{Introduction}

Final stature is achieved when the annual increase in height ceases and it is reflected by the fusion of the epiphyses of the hand, wrist and knees. The age of final height of boys is considered to be the 18 th year and in girls the 16th year of life. ${ }^{1}$ It is obvious that those who mature early stop growing earlier, whereas late maturers stop growing later than the average. However, final height should not be different irrespective of the age at onset of puberty, ${ }^{2,3}$ except in extreme situations of precocious or delayed puberty. In the growth charts that are in common use growth is recorded up to the age of 18 or 20 years. However, if one looks carefully at the growth chart, for example, of the $\mathrm{CDC}^{4}$ will notice an increase in the mean height of boys of about $1 \mathrm{~cm}$ from the age of 18 to 20 years denoting that there may be some increase after the age of 20 years. In contrast in the study of Tanner and Davies of North American children, ${ }^{5}$ no growth was observed in boys after the age of 18 years. In the currently used growth charts in Greece, ${ }^{6}$ for boys, there is $1 \mathrm{~cm}$ growth between 17 and 18 years of age, which is present also in the highest centiles, whereas in the lowest centiles the increase is even greater, denoting that that there is some growth after the age of 18 years. The aim of this study was to examine the age at final height in a large sample of Greek conscripts.

\section{Material and methods}

The study was based on anthropometric data of 3038 young male conscripts of the Greek Army. The data were collected from May to November 2006 and included all the men that enlisted in the Greek Army during that period (participation rate 100\%). The height of the conscripts was measured to the nearest millimeter by a Raven Minimeter portable height gauge. Measurements were performed in the morning hours, by a physician with a substantial measuring experience prior to the study, using the standard techniques. During measurements the conscripts were lightly dressed (underwear only) and without shoes.

\section{Data analysis}

Data are presented as mean with standard deviation (sd). We explored our data graphically using a locally weighted regression smoothed (lowess) curve. In order to describe more formally the linear growth of our population, and after having taken into account the form of the lowess curve, we adjusted a proper non-linear regression model to our data. Furthermore, we also adjusted a linear model in order to compare it with the previous non-linear one. We used F-test to estimate the significance of each of the two models, and Akaike's information criterion (AIC) to compare them

\section{Results}

We studied 3038 young males 18.11 to 26.97 years old. Mean (sd) age was 21.25 (2.31) years. The height of our population ranged from $153.8 \mathrm{~cm}$ to $203.5 \mathrm{~cm}$ and the mean (sd) height was 177.0 (6.9) $\mathrm{cm}$. Mean (sd) heights, by yearly age groups, are shown in Table 1 . The lowess curve showed a clear increment in the mean height of our population up to the age of about 23 years whereas, after this age the height seemed to be stable. The curvilinear form of the lowess curve (Figure 1), indicated that a negative exponential model would be appropriate for the description of the linear growth in our population. So, we adjusted a model of this kind (Figure 1) which took the form: $h=b_{1}\left(1-b_{2}{ }^{k}\right)$, where $h$ is the predicted from the model mean height, $b_{1}=180.16(95 \%$ C.I. $179.33-180.98, p<0.001)$ and represents the upper asymptote namely, the maximum mean height attained after theoretically infinite time, $b_{2}=0.823$ (95\% C.I. 0.813 $0.833, \mathrm{p}<0.001)$, and $\mathrm{k}=$ age in years. The model was highly significant $(\mathrm{p}<0.001)$ and $\mathrm{R}$ square was 0.9985 , i.e., the model explained $99.85 \%$ of the total variability of our data. Since from the form of the lowess curve seemed reasonable that a linear relationship between height and age may be a suitable alternative, we fitted a linear model, which was found to be statistically significant $(\mathrm{p}<0.001)$ too, and compared it with the previous non-linear one. The non-linear model provided a more adequate fit for the data compared with the linear one (respective AIC values: 18736.0 and 18738.6). 
Table I Mean (sd) height by yearly age groups

\begin{tabular}{llllllllll}
\hline (years) & $\mathbf{1 8 - 1 8 . 9 9}$ & $19-19.99$ & $\mathbf{2 0 - 2 0 . 9 9}$ & $\mathbf{2 1 - 2 1 . 9 9}$ & $\mathbf{2 2 - 2 2 . 9 9}$ & $\mathbf{2 3 - 2 3 . 9 9}$ & $\mathbf{2 4 - 2 4 . 9 9}$ & $\mathbf{2 5 - 2 5 . 9 9}$ & $\mathbf{2 6 - 2 6 . 9 9}$ \\
$\mathbf{n}$ & 443 & 949 & 275 & 267 & 271 & 318 & 287 & 142 & 86 \\
Mean (sd) & $175.7(6.8)$ & $175.6(6.5)$ & $176.3(6.4)$ & $177.6(7.0)$ & $177.9(7.0)$ & $178.3(7.1)$ & $178.6(6.9)$ & $178.4(6.7)$ & $178.4(7.6)$ \\
\hline
\end{tabular}

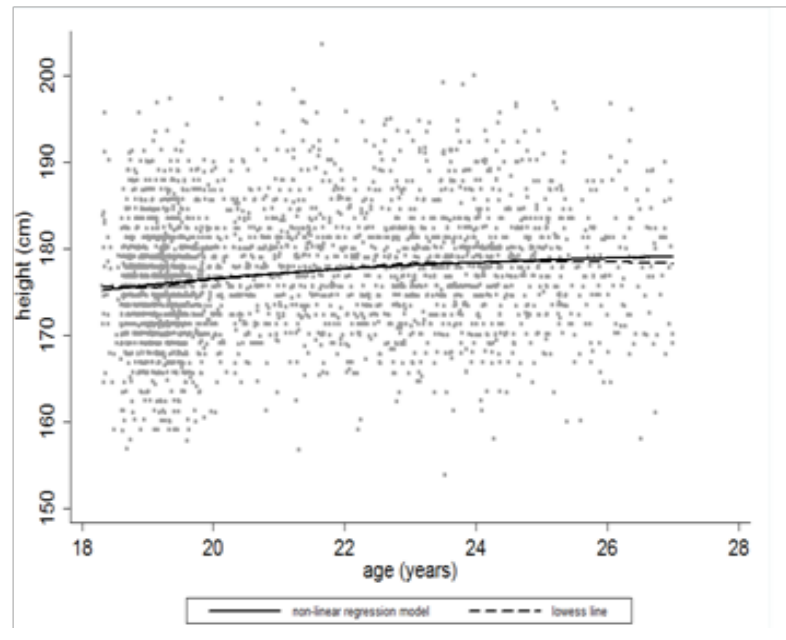

Figure I Scatter diagram, lowess curve of height for age, and graphical depiction of the nonlinear regression model describing the linear growth of our population. Dots represent the actual observations, dash line the lowess curve, and continuous line the predicted (by the non-linear model) mean height.

\section{Discussion}

According to Tanner adult stature is achieved when there is a annual increment in height of less than $1.0 \mathrm{~cm}^{7}$ Whereas, Largo et al defined adult stature as the height measured after 2 years of height gain of less than $0.5 \mathrm{~cm} .{ }^{8}$ Others have proposed that final height is attained when the epiphyses of the hand, wrist and knee have fused, although the latter cannot exclude a further increase in height due to growth of the spine. In this study we show that growth in the Greek young male population ceases at the age of 23 years. Although, most authors employ the age of 18 years as determining final height, ${ }^{9}$ older ages have been used as well. Olivier et al, in males registered at military service determined adult stature to be attained at the age of 19.5 years, ${ }^{10}$ whereas Gasser et al., ${ }^{11}$ Taranger \& Haag ${ }^{12}$ regarded the age at final height to be the 20 years. However, Hagg and Taranger in a small sample of longitudinally followed early, average and late maturing boys reported that in the latter final height was achieved at 25 years. ${ }^{13}$ Our data are cross-sectional so they cannot be considered as fully informative of the trend that underlies the linear growth of young males in the age range of 18 to 27 years. Nevertheless, the lowess curve depicted a clear increment in the mean height of our population up to the age of about 23 years, whereas, after this age the height seemed to be stable. Based in our data, we tried to construct a mathematical model that would describe adequately the linear growth in the population studied. The model $\left(h=b_{1}\left(1-b_{2}{ }^{k}\right)\right)$, which was proved to be statistically significant, provided a reliable approximation of the truly observed heights in our population. Our data show that growth in the average male ceases at the age of 23 years. This is contrary to the generally accepted notion of the age of 18-20 years as the age of attainment of adult stature. One possible explanation for the late achievement of final height is that a substantial number of the male present late onset of puberty, therefore they grow for a longer time period than the average maturer. This contrasts to most studies that report no difference in final height irrespective of the timing of the onset of puberty. However, in the study of Hagg \& Taranger ${ }^{13}$ only late maturing boys, and not girls, were taller than average maturers by $4.2 \mathrm{~cm}$. These differences, if proven to be due to late puberty, may be gender related because delayed puberty is much more common in boys. Our results cannot be generalized since our sample came from a cross-sectional and not a longitudinal study as well as a specific ethnic group. Nevertheless, our study provides a hint against the established notion of growth ceasing at the age of about 18 years, in males. More longitudinal studies are needed in order to depict more accurately the growth of males after the age of 18 years.

\section{Acknowledgement}

None.

\section{Conflict of interest}

The authors declare that they have no financial or non-financial competing interests.

\section{References}

1. Roche AF. Adult stature prediction: A critical review. Acta Medical Auxology. 1984;16:5-28.

2. Reiter EO, Rosenfeld RG. Normal and aberrant growth. In: Larsen, editor. Williams Textbook of Endocrinology, 10th ed. Elsevier, USA. 2003 ;1003-1114 p.

3. Pantsiotou S, Papadimitriou A, Douros K, et al. Maturational tempo differences in relation to the timing of the onset of puberty in girls. Acta Paediatr. 2008;97(2):217-220.

4. CDC growth charts.

5. Tanner JM, Davies PS. Clinical longitudinal standards for height and height velocity for North American children. $J$ Pediatr. 1985;107(3):317-329.

6. Chiotis D, Tsiftis G, Hatzisymeon M, et al. Height and weight of children of Hellenic origin aged 0-18 years (2000-2001): comparison with data collected during the period 1978-1979. Ann Clin Pediatr Univ Atheniensis. 2004;51:136-155.

7. Tanner JM, Whitehouse RH, Marubini E, et al. The adolescent growth spurt of boys and girls of the Harpenden growth study. Ann Hum Biol. 1976;3(2):109-126.

8. Largo RH, Gasser T, Prader A, et al. Analysis of the adolescent growth spurt using smoothing spline functions. Ann Hum Biol. 1978;5(5):421-434.

9. Kato S, Ashizawa K, Satoh K. An examination of the definition 'final height' for practical use. Ann Hum Biol. 1998;25(3):263-270.

10. Olivier G, Bressac F, Tissier H. Correlations between birth length and adult stature. Hum Biol. 1978;50(1):69-72.

11. Gasser T, Köhler W, Müller HG, Largo R, et al. Human height growth: correlational and multivariate structure of velocity and acceleration. Ann Hum Biol. 1985;12(6):501-515. 
12. Taranger J, Hagg U. The timing and duration of the adolescent growth. Acta Odontol Scand. 1980;38(1):57-67.

13. Hägg U, Taranger J. Height and height velocity in early, average and late maturers followed to the age of 25: a prospective longitudinal study of Swedish urban children from birth to adulthood. Ann Hum Biol. 1991;18(1):47-56. 